\title{
Factors affecting the absorption of iron from Fe(III)EDTA
}

\author{
By A. P. MAcPHAIL, T. H. BOTHWELL, ${ }^{*}$ J. D. TORRANCE, \\ D. P. DERMAN, W. R. BEZWODA AND R. W. CHARLTON \\ Joint University/South African MRC Iron and Red Cell Metabolism Unit, Department of \\ Medicine, University of the Witwatersrand, Johannesburg, South Africa
}

\author{
AND FATIMA MAYET \\ Department of Medicine, University of Natal, Durban, South Africa
}

(Received 20 June 1980 - Accepted 24 July 1980)

\begin{abstract}
1. The modification of iron absorption from Fe(III)EDTA by agents known to promote or inhibit absorption was examined in 101 volunteer multiparous Indian women. Fe absorption from Fe(III)EDTA was compared with absorption of intrinsic food $\mathrm{Fe}$ in a further twenty-eight subjects. Finally the urinary excretion of radio-Fe after oral administration of ${ }^{59} \mathrm{Fe}$ (III)EDTA was studied in twenty-four subjects and evidence of intraluminal exchange of $\mathrm{Fe}$ was examined.

2. Fe absorption from maize porridge fortified with Fe(III)EDTA was more than twice that from porridge fortified with $\mathrm{FeSO}_{4} \cdot 7 \mathrm{H}_{2} \mathrm{O}$.

3. Although bran decreased $\mathrm{Fe}$ absorption from $\mathrm{FeSO}_{4} \cdot 7 \mathrm{H}_{2} \mathrm{O}$ approximately 11 -fold, it had no significant effect on Fe absorption from Fe(III)EDTA. Nevertheless tea, which is a more potent inhibitor of Fe absorption, decreased absorption from Fe(III)EDTA 7-fold.

4. Fe absorption from Fe(III)EDTA given in water was only increased $40 \%$ by addition of 3 mol ascorbic acid/mol Fe but by 7 -fold when the relative proportions were increased to $6: 1$. This enhancing effect was blunted when the $\mathrm{Fe}$ (III)EDTA was given with maize porridge. In these circumstances, an ascorbate:iron value of 3:1 (which doubles absorption from $\mathrm{FeSO}_{4} .7 \mathrm{H}_{2} \mathrm{O}$ ) produced no significant increase in $\mathrm{Fe}$ absorption, while a value of $6: 1$ produced only a $2 \cdot 5$-fold increase.

5. Fe absorption from Fe(III)EDTA was not altered by addition of maize porridge unless ascorbic acid was present.

6. Less than $1 \%$ of ${ }^{59} \mathrm{Fe}$ administered as ${ }^{59} \mathrm{Fe}$ (III)EDTA was excreted in the urine and there was an inverse relationship between $\mathrm{Fe}$ absorption and the amounts excreted $(r 0.58, P<0.05)$.

7. Isotope exchange between ${ }^{35} \mathrm{Fe}$ (III)EDTA and ${ }^{59} \mathrm{FeSO}_{4} .7 \mathrm{H}_{2} \mathrm{O}$ was demonstrated by finding a similar relative value for the two isotopes in urine and erythrocytes when the two labelled compounds were given together orally. This finding was confirmed by in vitro studies, which showed enhanced ${ }^{59} \mathrm{Fe}$ solubilization from ${ }^{59} \mathrm{FeSO}_{4} \cdot{ }^{7} \mathrm{H}_{2} \mathrm{O}$ in maize porridge when unlabelled Fe(III)EDTA was added.

8. Although Fe absorption from Fe(III)EDTA was marginally higher it appeared to form a common pool with intrinsic food iron in most studies. It is postulated that the mechanism whereby Fe(III)EDTA forms a common pool with intrinsic food Fe differs from that occurring with simple Fe salts. When Fe is present in the chelated form it remains in solution and is relatively well absorbed because it is protected from inhibitory ligands. Simple Fe salts, however, are not similarly protected and are absorbed as poorly as the intrinsic food Fe.

9. It is concluded that Fe(III)EDTA may be a useful compound for food fortification of cereals because the $\mathrm{Fe}$ is well absorbed and utilized for haemoglobin synthesis. The substances in cereals which inhibit absorption of simple Fe salts do not appear to inhibit absorption of Fe from Fe(III)EDTA.
\end{abstract}

The high incidence of iron deficiency in populations subsisting on cereal-based diets is largely due to the poor absorption of Fe from these foodstuffs. For example, the results of previous studies indicated that the geometric mean absorption of $\mathrm{Fe}$ from rice and maize in $\mathrm{Fe}$ deficient subjects was less than 5\% (Sayers et al. 1973; Sayers, Lynch, Charlton \& Bothwell, 1974; Sayers, Lynch, Charlton, Bothwell et al. 1974; Derman et al. 1977). These results underline the need for Fe-fortification programmes in populations subsisting on mainly

* For reprints. 
cereal-based diets. Unfortunately, such programmes have not been successful in the past, since the Fe salts used for fortification are as poorly absorbed as the intrinsic Fe present in various cereals (Layrisse et al. 1973). This can be ascribed to the fact that the ligands inhibiting the absorption of the food Fe, have the same effect on the added Fe. One way of overcoming this problem has been to add ligands, such as ascorbic acid, which enhance Fe absorption (Sayers et al. 1973; Sayers, Lynch, Charlton \& Bothwell, 1974; Sayers, Lynch, Charlton, Bothwell et al. 1974; Disler, Lynch, Charlton, Bothwell et al. 1975). While ascorbic acid has been shown to be effective, it has been difficult to find a suitable vehicle to which to add it, since it is a highly-reactive compound, which is easily oxidized and which sometimes causes unacceptable colour changes in food (Sayers, Lynch, Charlton, Bothwell et al. 1974). The results of recent work suggest that an alternative approach may be promising. It has been shown that the Fe present in the Fe(III)EDTA compound is better absorbed in the presence of a meal than is the $\mathrm{Fe}$ in other salts, possibly due to the fact that it is less susceptible to inhibitory ligands which form insoluble complexes with $\mathrm{Fe}$ (Layrisse \& Martinez-Torres, 1977; Martinez-Torres et al. 1979).

In the present study further information was obtained on the absorption of Fe from $\mathrm{Fe}$ (III)EDTA and on the effects of various foods and of inhibitory and promoting ligands. In addition, information was obtained on the intraluminal mixing of $\mathrm{Fe}$ and on the excretion of $\mathrm{Fe}(\mathrm{III}) \mathrm{EDTA}$ in the urine.

\section{EXPERIMENTAL}

Subjects

The subjects were 153 multiparous Indian housewives aged between 21 and 71 years (mean 36 years) living in a municipal housing complex at Chatsworth, near Durban. They belong to a low socio-economic group in which Fe deficiency is common (Mayet et al. 1972).

\section{Preparation and administration of the meals}

Sufficient maize meal to provide $50 \mathrm{~g}$ dry maize meal/subject was mixed with a small amount of water to make a paste. This was added to four times its weight of boiling water and cooked at $90^{\circ}$ for $20-25 \mathrm{~min}$ to make a porridge. When intrinsically-labelled maize (Hussain et al. 1965; Layrisse et al. 1969) was used, sufficient to provide $3 \mu \mathrm{Ci}{ }^{55} \mathrm{Fe} /$ subject was blended with dry carrier maize to provide $50 \mathrm{~g}$ dry maize/subject. In some experiments the meal was fortified with 3 or $5 \mathrm{mg}$ Fe labelled with $3 \mu \mathrm{Ci} /$ subject by mixing the appropriate radio-Fe compound into the paste. In other experiments the porridge was cooked without added $\mathrm{Fe}$ and individual servings were subsequently fortified by adding $3 \mathrm{ml}$ portions of solutions containing 3 or $5 \mathrm{mg}$ of $\mathrm{Fe}$ either as $\mathrm{Fe}$ (III)EDTA in water or as $\mathrm{FeSO}_{4} \cdot 7 \mathrm{H}_{2} \mathrm{O}$ in $0.01 \mathrm{M}$-hydrochloric acid. In each instance the portion contained $3 \mu \mathrm{Ci}$ of the appropriate radio-Fe labelled compound. The final mass of porridge eaten by each subject was $250 \mathrm{~g}$. Tea was made by adding $45 \mathrm{~g}$ leaves (Pot o' Gold; O.K. Bazaars Ltd, Johannesburg) to $1800 \mathrm{ml}$ boiling water to provide $200 \mathrm{ml} / \mathrm{subject}$. The tea was sweetened with cane sugar fortified with the appropriate radio-Fe compound. The traditional Indian dhal (Sayers, Lynch, Charlton \& Bothwell, 1974) and the fortified sugar (Disler, Lynch, Charlton, Bothwell et al. 1975) were prepared as described previously.

In each study the meal was consumed after an overnight fast and no food or drink was allowed for $4 \mathrm{~h}$ after the test meal had been eaten. The same procedure was followed the next day, but the meal was labelled with the other Fe isotope. After a period of 2 weeks, blood samples were taken after an overnight fast for the determination of the concentrations of ${ }^{59} \mathrm{Fe}$ and ${ }^{55} \mathrm{Fe}$, haemoglobin, serum $\mathrm{Fe}$, unsaturated Fe-binding capacity and serum ferritin. Each subject then drank a 'reference Fe salt' consisting of $50 \mathrm{ml}$ of a solution 
containing $30 \mathrm{mg}$ ascorbic acid and $3 \mathrm{mg} \mathrm{Fe}$ as ${ }^{59} \mathrm{FeSO}_{4} \cdot 7 \mathrm{H}_{2} \mathrm{O}\left(3 \mu \mathrm{Ci}{ }^{59} \mathrm{Fe}\right)$. No food or drink was allowed for the following $4 \mathrm{~h}$ period. Samples of blood were again obtained a further 2 weeks later and the ${ }^{59} \mathrm{Fe}$ concentrations determined. The percentage absorption of the $\mathrm{Fe}$ from the solution was calculated by difference and provided an index of each individual's absorbing capacity.

\section{Isotopic and chemical methods}

Labelled Fe(III)EDTA was prepared by mixing equimolar solutions of disodium EDTA and carrier ferric chloride with a tracer amount of radio-labelled $\mathrm{FeCl}_{3}$. The $\mathrm{pH}$ of the solution was then adjusted to $\mathrm{pH} 5$ with sodium bicarbonate. The Fe(III)EDTA complex formed was precipitated by ethanol, the supernatant fraction discarded and the precipitate redissolved in water. The complex was then precipitated again with ethanol and washed three times with ethanol (Sawyer \& McKinnie, 1960).

Duplicate blood samples $(10 \mathrm{ml})$ and appropriate standards were prepared for differential radioactivity determination by the method of Katz et al. (1964). The quantities of ${ }^{55} \mathrm{Fe}$ and ${ }^{59} \mathrm{Fe}$ in the processed samples were determined using a liquid-scintillation system (Insta-Gel; Tri-Carb AAA Spectrometer model No. 3375; Packard Instrument Co., Downers Grove, Illinois, USA). The ${ }^{59} \mathrm{Fe}$ activity in the $4 \mathrm{ml}$ blood samples collected immediately before the 'reference Fe salt' was administered, and 2 weeks later, was assessed against suitable standards using a liquid-scintillation spectrometer (Auto-Gamma Tri-Carb Spectrometer model No. 3001; Packard Instrument Co.). All values for absorption (\%) were calculated on the assumption that $100 \%$ of the absorbed radioactivity was present in the haemoglobin of circulating erythrocytes, and that the blood volume of each subject was $65 \mathrm{ml} / \mathrm{kg}$. Although the red cell utilization of radioiron varies according to iron status, it is normally above $80 \%$ and in an iron deficient group such as the one investigated in the present study, most values would be expected to be close to $100 \%$. Furthermore, any errors introduced by the assumption would not invalidate the findings, since the design of the absorption experiments was such that each subject served as her own control, with comparisons being made on the basis of paired data and not between different individuals.

When large volumes of urine were prepared for the determination of differential radioactivity using the same method as for blood, a black compound was obtained which was unsuitable for mixing in insta-gel. To overcome this problem, half the volume of urine passed was evaporated to $10-15 \mathrm{ml}$ by gentle boiling and prepared according to the method used for blood samples. The resulting black compound was dissolved in $1 \mathrm{M}-\mathrm{HCl}$ and all the Fe was converted to the ferric state by the addition of potassium permanganate solution. The ferric-Fe was complexed with potassium thiocyanate and immediately extracted with diethyl ether. The water phase was found to be free of radioactivity after four to five diethyl ether extractions. The diethyl ether phase was evaporated to dryness and then redigested and prepared for radioactivity determination as described previously.

Serum Fe concentrations were measured by the International Committee for Standardization in Haematology (1978) method and the unsaturated Fe-binding capacity was determined by the method of Herbert et al. (1967). The Fe content of digested samples of food was estimated by a modification (Bothwell et al. 1979) of the method of Lorber (1927). The serum ferritin concentrations were measured by radioimmunoassay using the method of Deppe et al. (1978).

The in vitro experiments were done using a modification of a method described previously (Bezwoda et al. 1978). In place of the bread used in the original method, a soft maize porridge was prepared using $70 \mathrm{~g}$ dry maize meal/l water. This was fortified with $3 \mathrm{mg} \mathrm{Fe}$ in the form of the appropriate radio-Fe compound. Equal weighed portions of the porridge were then incubated in duplicate for $30 \mathrm{~min}$ at room temperature in $5 \mathrm{ml} \mathrm{HCl}$ solutions 
covering the $\mathrm{pH}$ range $0 \cdot 5-6 \cdot 0$. Portions of the supernatant fraction were counted after centrifugation at $3000 \mathrm{~g}$ and the percentage $\mathrm{Fe}$ in solution was calculated.

\section{Ethical considerations}

Written consent was obtained from all subjects after the nature of the investigation had been explained to them by an Indian social worker. Before starting the study approval was obtained from the Committee for Research on Human Subjects of the Faculty of Medicine, University of the Witwatersrand, Johannesburg. With regard to radiation exposure, it was calculated that if the entire test dose of radioisotope was retained, the total radiation averaged over 13 weeks would be approximately $20 \%$ and $0 \cdot 2 \%$ of the permissible whole-body burden for continuous exposure to ${ }^{59} \mathrm{Fe}$ and ${ }^{55} \mathrm{Fe}$ respectively (International Commission for Radiation Protection, 1960).

\section{Statistical methods}

Serum ferritin and $\mathrm{Fe}$ absorption values in individual experiments showed considerable variation. All values were therefore logarithmically transformed in order to correct for positive skew. Since all results were expressed as geometric means and standard deviation ranges, standard parametric statistical methods could be used.

\section{RESULTS}

Comparison of the absorption of Fe from maize-meal porridge fortified with $\mathrm{FeSO}_{4} \cdot 7 \mathrm{H}_{2} \mathrm{O}$ or with $\mathrm{Fe}(I I I) E D T A$

In order to establish whether the absorption of $\mathrm{Fe}$ from $\mathrm{FeSO}_{4} \cdot 7 \mathrm{H}_{2} \mathrm{O}$ and $\mathrm{Fe}(\mathrm{III}) \mathrm{EDTA}$ differed, twelve subjects were given $\mathrm{FeSO}_{2} .7 \mathrm{H}_{2} \mathrm{O}$-fortified maize porridge on one morning and a similar $\mathrm{Fe}$ (III)EDTA-fortified porridge the following morning. Table 1 shows that the geometric mean $\mathrm{Fe}$ absorption (\%) from the Fe(III)EDTA fortified meal (7.2) was significantly greater than from the $\mathrm{FeSO}_{4} .7 \mathrm{H}_{2} \mathrm{O}$ fortified meal $(3.5)(t 5.5, P<0.001)$.

\section{The effect of inhibitors on $\mathrm{Fe}$ absarption from $\mathrm{Fe}(\mathrm{III}) \mathrm{EDTA}$}

The 2-fold increase in $\mathrm{Fe}$ absorption found in the first study suggested that $\mathrm{Fe}$ in the $\mathrm{Fe}(\mathrm{III})$ EDTA complex is protected from the inhibitors of Fe absorption present in maize porridge. It was therefore decided to determine whether known inhibitors of Fe absorption, such as bran and tea, had any effect on Fe absorption from Fe(III)EDTA.

In order to assess the effect of bran on Fe absorption, 9 subjects drank $100 \mathrm{ml}$ water sweetened with sugar fortified with $\mathrm{FeSO}_{4} .7 \mathrm{H}_{2} \mathrm{O}$ on one morning while on the second morning $10 \mathrm{~g}$ bran was mixed with the Fe-fortified water (Table 2). Bran reduced the geometric mean absorption 11 -fold, from (\%) 16.5 to $1.5(t 16.5, P<0.001)$. In a second study, which was carried out in ten subjects, $\mathrm{FeSO}_{4} \cdot 7 \mathrm{H}_{2} \mathrm{O}$ was replaced by $\mathrm{Fe}$ (III)EDTA. There was no significant difference between the mean geometric absorption from $\mathrm{Fe}(\mathrm{III})$ EDTA without bran (10.3) and with bran (8.4) $(t 1.4, P>0.1)$.

As tea is known to be a potent inhibitor of $\mathrm{Fe}$ absorption (Disler, Lynch, Charlton, Torrance $e t$ al. 1975), a similar study was performed in eight subjects using black tea instead of bran. The geometric mean $\mathrm{Fe}$ absorption from $\mathrm{Fe}(\mathrm{III}) \mathrm{EDTA}$ was reduced approximately 7 -fold from 19.2 to 2.8 , by the addition of tea $(t 10.35, P<0.001)$.

The effect of increasing doses of ascorbic acid on the absorption of Fe from $\mathrm{Fe}(I I I) E D T A$ As the $\mathrm{Fe}$ in $\mathrm{Fe}(\mathrm{III}) \mathrm{EDTA}$ seemed to be protected to some extent from inhibitory ligands, the effect of a known promoter of Fe absorption, namely ascorbic acid, was studied. Two series of three experiments were done to find out whether increasing doses of ascorbic acid improved $\mathrm{Fe}$ absorption from $\mathrm{Fe}$ (III)EDTA. In the first set of experiments the Fe(III)EDTA 


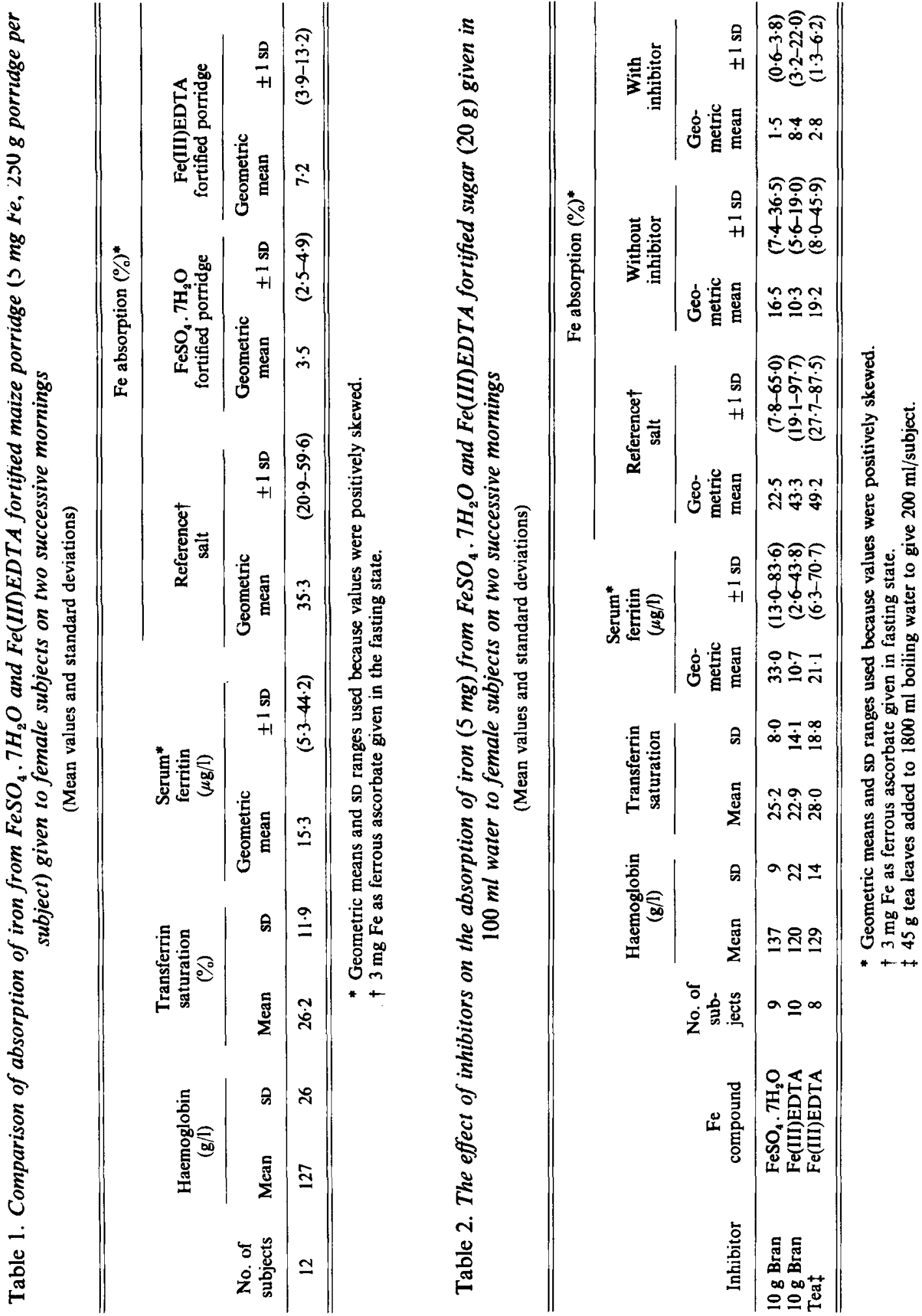


was administered in water alone, while in the second set it was administered in maize porridge. In each study the meal was given on one of the days with ascorbic acid and on the other, without ascorbic acid. At the completion of each absorption study, a further one was done in which the absorption of a reference dose of $3 \mathrm{mg} F e$ as ferrous ascorbate was measured. In this way it was possible not only to express the actual results obtained but also to standardize individual results to a $40 \%$ reference absorption, which has been used as a means of comparing the findings in individuals or groups with differing avidities for Fe (Hallberg et al. 1978).

When the unstandardized values were analysed (Table 3), it was clear that $25 \mathrm{mg}$ ascorbic acid had no effect on the absorption of Fe from $\mathrm{Fe}$ (III)EDTA when administered in water or porridge $(t 0.24, P>0.1 ; t 1.03, P>0.1$ respectively). With the $50 \mathrm{mg}$ dose there was a modest, but significant increase $(t 2 \cdot 84, P<0.05)$ in Fe absorption when Fe(III)EDTA was given in water but none when it was given in porridge $(t 0.38, P>0 \cdot 1)$. A dose of $100 \mathrm{mg}$ ascorbic acid caused a more than 6-fold increase $(t 6.23, P<0.01)$ in Fe absorption when the Fe(III)EDTA was given in water and a 2 -fold increase $(t 5.71, P<0.01)$ when it wàs given in porridge.

When the standardized absorptions of Fe from Fe(III)EDTA in water were compared with those obtained from Fe(III)EDTA-fortified porridge (Table 3), both in the absence of ascorbic acid, it was apparent that the addition of $250 \mathrm{~g}$ maize-meal porridge had little or no effect on the absorption from Fe(III)EDTA $(F 1 \cdot 3, P>0 \cdot 1)$. However, when $100 \mathrm{mg}$ ascorbic acid was present, the standardized absorption $(\%)$ was significantly reduced from a geometric mean of 44 to 15.6 by the presence of maize porridge $(t 1.93, P<0.05)$.

\section{Comparison between the absorption of intrinsically-labelled cereals and ${ }^{59} \mathrm{Fe}($ III)EDTA}

Three different meals were used to compare the absorption of intrinsically labelled food $\mathrm{Fe}$ and $\mathrm{Fe}(\mathrm{III}) \mathrm{EDTA}$. Two experiments were done using maize poridge as in the previous studies. In the first of these experiments (Table 4) sugar fortified with ${ }^{59} \mathrm{Fe}$ (III)EDTA was sprinkled on the cooked maize porridge intrinsically labelled with ${ }^{55} \mathrm{Fe}$ and the porridge was eaten immediately. The geometric mean absorption from the extrinsic Fe(III)EDTA $(\%)(12.9)$ was more than double that from the intrinsic label (4.9) $(t 3.74, P<0.005)$. This suggested that the $\mathrm{Fe}$ in the form of $\mathrm{Fe}$ (III)EDTA was protected from inhibitory ligands in the maize, while the intrinsic Fe was not. However, since the two labels were not cooked together, the study was repeated and the ${ }^{59} \mathrm{Fe}$ (III)EDTA was added before cooking. When this was done there was no significant difference in the absorption of the intrinsic Fe and the extrinsic Fe administered as Fe(III)EDTA $(t 2 \cdot 05, P>0 \cdot 1)$. The observation was confirmed in another similar study (Table 4) in which ${ }^{59} \mathrm{Fe}$ (III)EDTA was added to a traditional intrinsically-labelled pea dhal before cooking. Although the absorption of the $\mathrm{Fe}$ in ${ }^{59} \mathrm{Fe}$ (III)EDTA was marginally greater in each subject there was no significant difference between the geometric mean absorptions $(t 0.88, P>0 \cdot 1)$, and the ratio of the geometric mean absorption from extrinsic Fe to corresponding value for intrinsic food $\mathrm{Fe}$ was close to unity.

\section{Excretion of $\mathrm{Fe}(I I I) E D T A$ in the urine}

Since EDTA chelates are excreted by the kidney (Will \& Vilter, 1954) a study was undertaken to assess whether Fe given orally as Fe(III)EDTA appeared in the urine. Fourteen fasting subjects with normal renal function drank $100 \mathrm{ml}$ water sweetened with $10 \mathrm{mg}$ sugar fortified with $5 \mathrm{mg}$ Fe as ${ }^{59} \mathrm{Fe}$ (III)EDTA. The total urine output for the next $24 \mathrm{~h}$ was collected and the percentage of the dose of ${ }^{59} \mathrm{Fe}$ appearing in the urine was compared to that absorbed (Fig. 1). In all instances less than $1 \%$ of the administered dose appeared in the urine (geometric mean $0.32 \%$, SD range $0.18-0.60$ ) and serial sampling showed that all the radio-Fe was excreted in the first $24 \mathrm{~h}$. A significant inverse relationship 


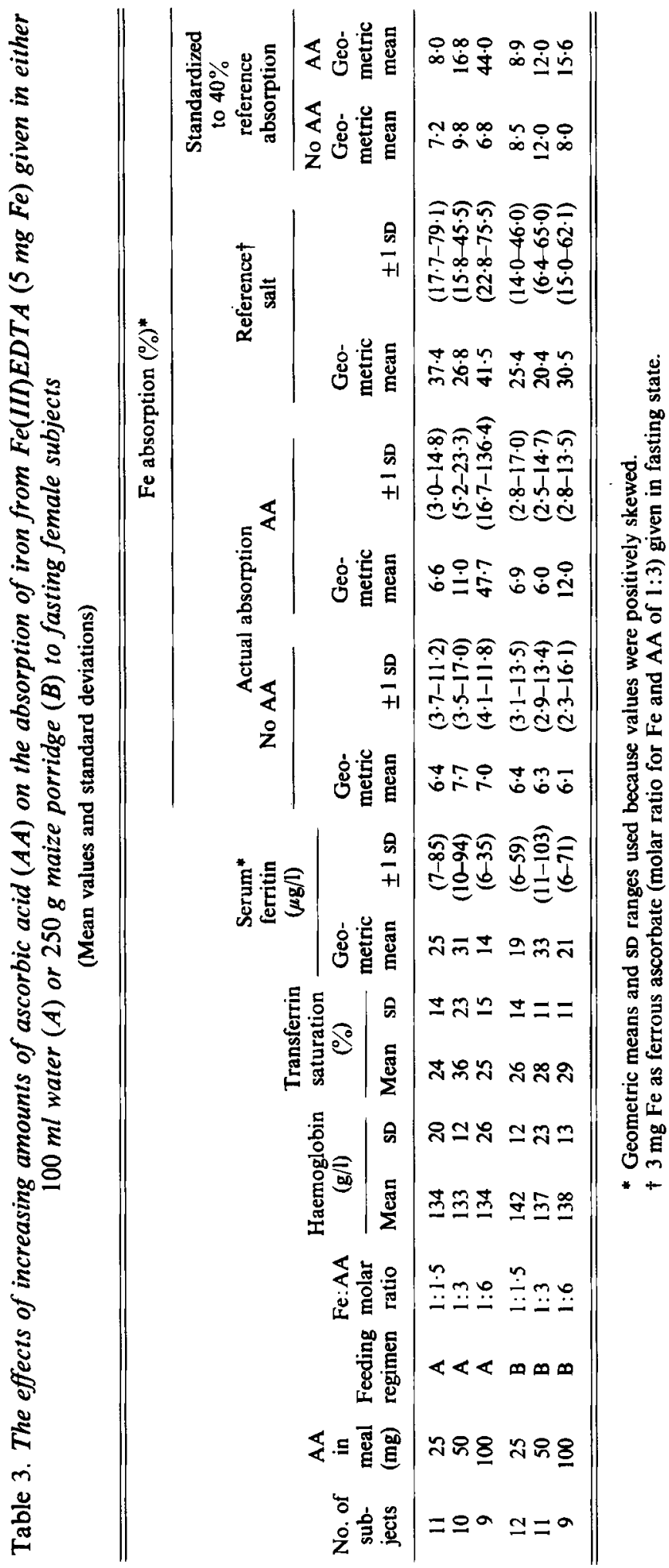




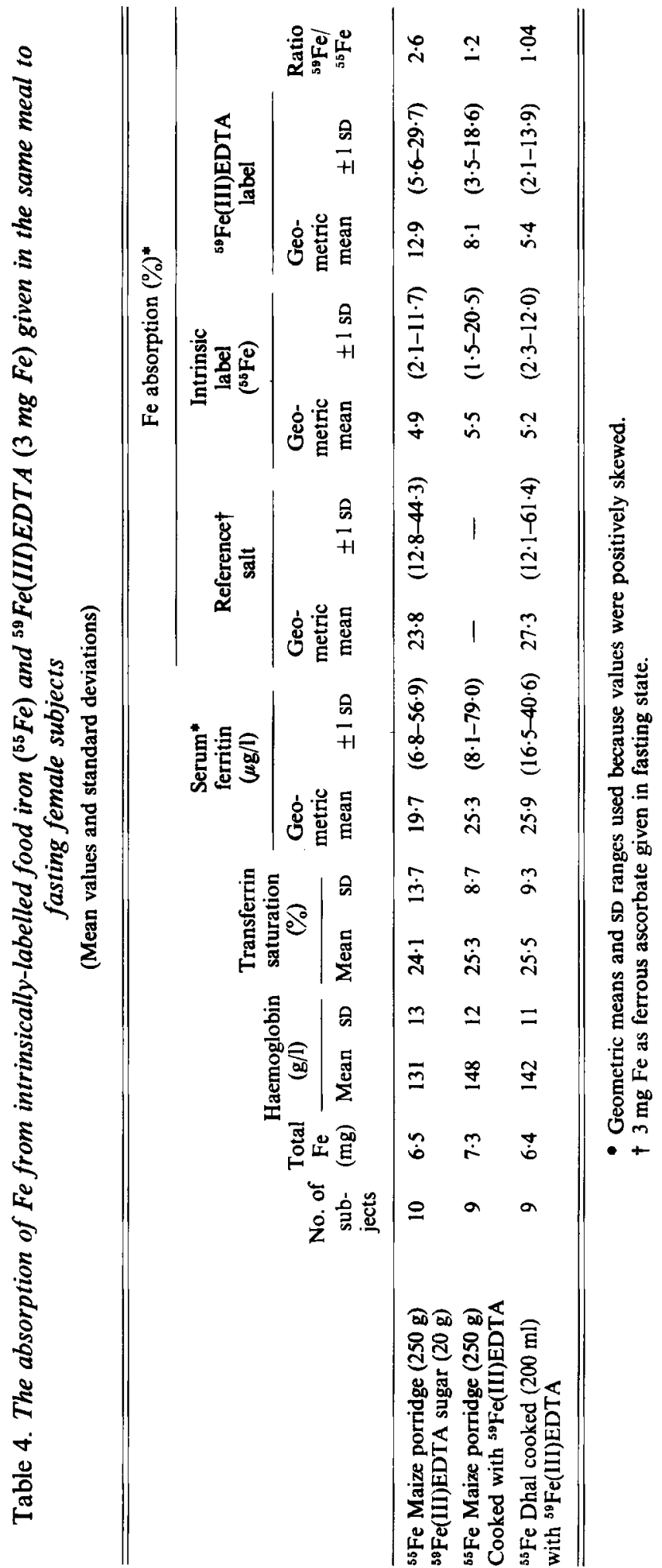




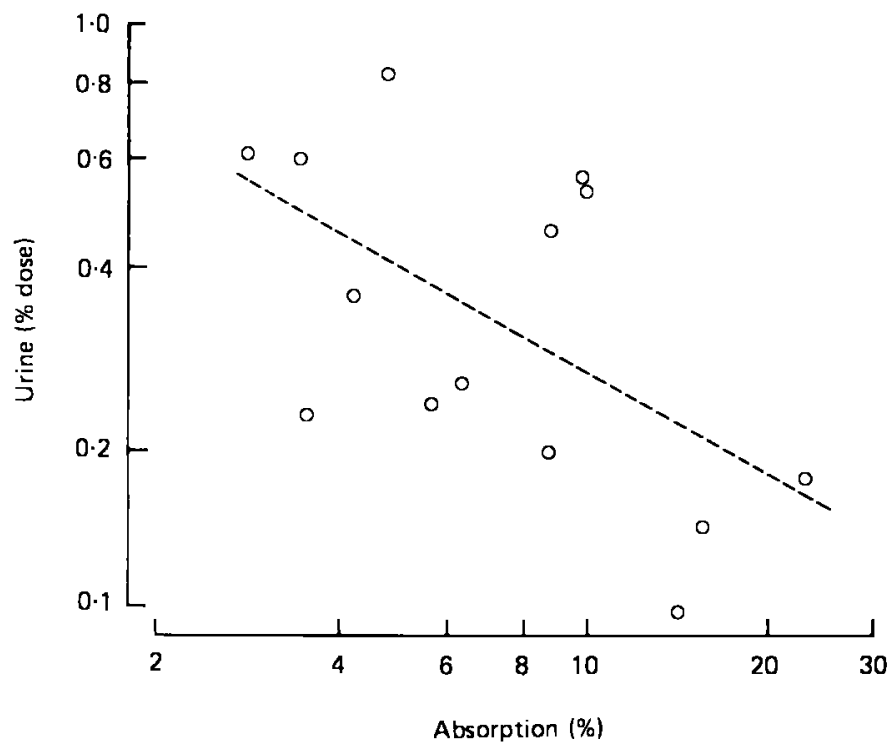

Fig. 1. The relationship between the excretion of ${ }^{8} \mathrm{Fe}$ in the urine collected over $24 \mathrm{~h}(\%$ dose) and the absorption of ${ }^{59} \mathrm{Fe}$ from $3 \mathrm{mg} \mathrm{Fe}$ as ${ }^{59} \mathrm{Fe}$ (III)EDTA given in water to fourteen subjects after an overnight fast $(r-0.58, P<0.05)$.

was noted between the logarithm of the percentage of the dose absorbed and that excreted in the urine $(r-0.58, P<0.05)$.

The appearance of radio-Fe in the urine provided a means whereby intraluminal exchange of Fe could be studied. A similar study was therefore carried out in ten subjects using two isotopes of $\mathrm{Fe}$. Equimolar quantities of ${ }^{55} \mathrm{Fe}$ (III)EDTA and ${ }^{59} \mathrm{FeSO}_{4} .7 \mathrm{H}_{2} \mathrm{O}$ were mixed into a $250 \mathrm{~g}$ maize porridge after cooking. The mean for absorption of ${ }^{55} \mathrm{Fe}$ : absorption of ${ }^{50} \mathrm{Fe}$ from the meal was $1.22( \pm 0.11)$ which was similar to the value of $1.28( \pm 0.08)$ found in the urine $(t 2 \cdot 19, P>0.05)$. Since these results suggested that there was some exchange between the isotopes an in vitro experiment was performed using a modification of a method described by Bezwoda et al. (1978) in order to try and verify the point. The solubilization of ${ }^{59} \mathrm{Fe}$ from portions of cooked maize meal, fortified with ${ }^{59} \mathrm{FeSO}_{4} \cdot 7 \mathrm{H}_{2} \mathrm{O}$ or ${ }^{59} \mathrm{Fe}$ (III)EDTA, at various $\mathrm{pH}$ values is shown in Fig. 2 . The percentage ${ }^{59} \mathrm{Fe}$ appearing in the supernatant fraction at $\mathrm{pH}$ values greater than those normally found in the stomach was lowest when ${ }^{59} \mathrm{FeSO}_{4} \cdot 7 \mathrm{H}_{2} \mathrm{O}$ was used alone and highest when ${ }^{59} \mathrm{Fe}(\mathrm{III}) \mathrm{EDTA}$ was used alone. However, if an equimolar quantity of unlabelled $\mathrm{Fe}$ (III)EDTA was added to the ${ }^{59} \mathrm{FeSO}_{4} \cdot 7 \mathrm{H}_{2} \mathrm{O}$ fortified maize the percentage ${ }^{59} \mathrm{Fe}$ appearing in the supernatant fraction increased markedly, shifting the curve to approximately midway between that produced by ${ }^{59} \mathrm{Fe}(\mathrm{III}) \mathrm{EDTA}$ alone and ${ }^{59} \mathrm{FeSO}_{4} \cdot 7 \mathrm{H}_{2} \mathrm{O}$ alone.

\section{DISCUSSION}

The prevalence of Fe deficiency has been shown to be approximately $26 \%$ in the population from which the Indian women who volunteered for the absorption studies was drawn (Mayet et al. 1972). The current findings tend to confirm this in that in none of the groups did the geometric mean of the serum ferritin concentration exceed the normal adult female value of $35 \mu \mathrm{g} / \mathrm{l}$ (Jacbos et al. 1972). In addition, the over-all mean absorption (\%) of $3 \mathrm{mg} \mathrm{Fe}$ as ferrous ascorbate was $31 \cdot 0(14 \cdot 3-67 \cdot 6)$, which can be taken as further evidence that the over-all group was avid for Fe (Kuhn et al. 1968). This background of Fe deficiency gave 


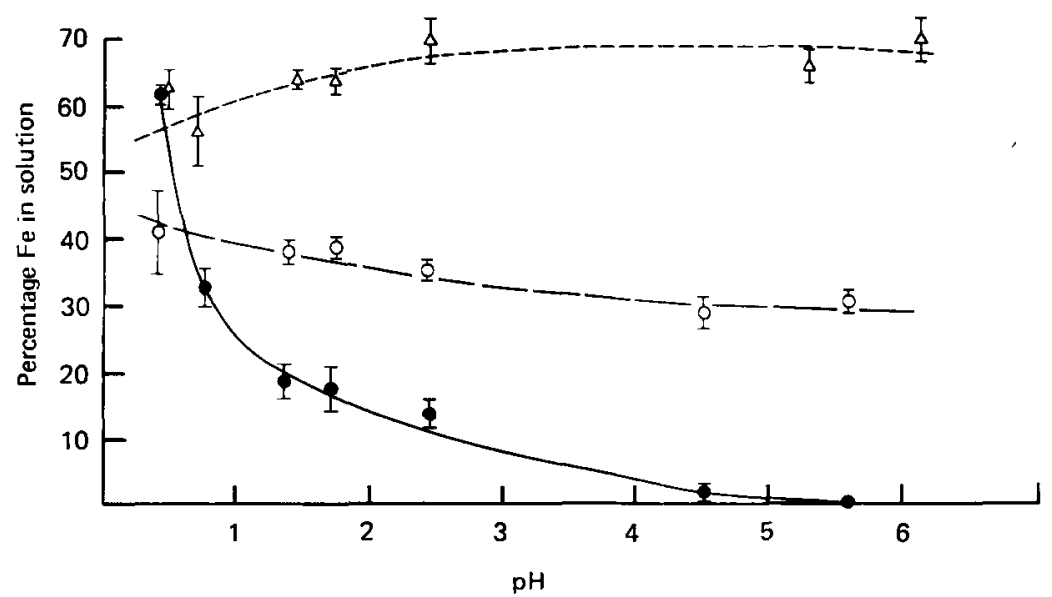

Fig. 2. The percentage ${ }^{59} \mathrm{Fe}$ appearing in the supernatant fraction after incubation of portions of maize porridge fortified with $\mathrm{Fe}$ at various $\mathrm{pH}$ values. (O-O) ${ }^{58} \mathrm{FeSO}_{4} .7 \mathrm{H}_{2} \mathrm{O} ;(\triangle-\triangle)^{59} \mathrm{Fe}$ (III)EDTA; $(\mathrm{O}-\mathrm{O}){ }^{59} \mathrm{FeSO}_{4}, 7 \mathrm{H}_{2} \mathrm{O}$ and $\mathrm{Fe}$ (III)EDTA. Results are the mean values with their standard errors represented by vertical bars of three experiments done in duplicate.

added relevance to the in vivo Fe absorption findings, since it is to target populations such as this that Fe-fortification programmes should be directed. However, a major deterrent to the mounting of such programmes is the fact that the fortification-Fe is as poorly absorbed as is the intrinsic Fe present in cereal staples (Layrisse et al. 1973). In addition, ionizable Fe salts can produce a number of undesirable colour changes in food and can adversely affect the storage properties of certain foods (International Nutritional Anemia Consultative Group, 1977). It is against this background that the current findings should be seen.

The chelator EDTA forms a very stable complex with $\mathrm{Fe}$ and because of this the $\mathrm{Fe}$ (III)EDTA complex might be expected to be protected to some extent from the ligands in cereals which inhibit $\mathrm{Fe}$ absorption. The results of the present investigation confirmed that $\mathrm{Fe}$ (III)EDTA was well absorbed and utilized for haemoglobin formation and that its absorption was not inhibited by bran or maize porridge. Nevertheless more powerful inhibitors of absorption such as tea were able to dricase the absorption of $\mathrm{Fe}$ from Fe(III)EDTA. The absorption of Fe(III)EDTA was als $r$ altered by the addition of ascorbic acid. In the absence of inhibitors (Table $3 \mathrm{~A}$ ) ascorbic id did promote Fe absorption from Fe(III)EDTA in a similar dose-dependent manner ic that which has been previously demonstrated with simple Fe salts (Sayers et al. 1973; sa .rs, Lynch, Charlton \& Bothwell, 1974; Sayers, Lynch, Charlton, Bothwell et al. 1974; $1 ;$ i-Rasmussen \& Hallberg, 1974). Thus, when present at sufficiently-high concentration ascorbate was able to compete successfully for the $\mathrm{Fe}$ in $\mathrm{Fe}$ (III)EDTA. There were, however, quantitative differences between the behaviour of Fe(III)EDTA and simple Fe salts. For example, in one study (Table 3 ) the absorption (\%) of Fe from Fe(III)EDTA alone was $7 \cdot 7$ compared with 26.8 from the ferrous ascorbate reference salt. When ascorbate was added to give a molar ratio of 3:1 for ascorbate and $\mathrm{Fe}$ (which is the same as that in the reference salt) absorption increased to only 11 . This result suggests that perhaps one-sixth of the Fe was transferred to ascorbate in the presence of a 3-fold molar excess of ascorbic acid. Fe absorption from $\mathrm{Fe}$ (III)EDTA was increased to the same level as that from the reference salt only when the molar ratio for ascorbate and $\mathrm{Fe}$ was $6: 1$. Under such circumstances all the $\mathrm{Fe}$ was presumably in the form of ascorbate. In the presence of maize there was no improvement 
in the absorption of Fe from Fe(III)EDTA until a molar ratio for ascorbate and Fe of 6:1 was present and even then the increase was a modest one, from a standardized absorption $(\%)$ of approximately $8-15.6$. These results suggest that although ascorbate $\mathrm{Fe}$ is very well absorbed its absorption was reduced considerably (from 44 to 15) by the presence of maize porridge. On the other hand, the standardized absorption of EDTA-complexed $\mathrm{Fe}$, although only $6-10$, was not significantly affected by the presence of the maize porridge. In this context, the unchanged absorption of $\mathrm{Fe}$ from $\mathrm{Fe}$ (III)EDTA in maize porridge when the molar ratio for ascorbate and Fe was $1: 3$ is not surprising if it is accepted that only one-sixth of the $\mathrm{Fe}$ was present as the ascorbate complex and that only approximately $12 \%$ of this was absorbed (Table 3). These results suggest that competitive binding of Fe occurs in the gastrointestinal tract and that the amount of $\mathrm{Fe}$ absorbed depends on the relative affinities for $\mathrm{Fe}$ of the various ligands which either promote or inhibit $\mathrm{Fe}$ absorption.

Most Fe salts which are added as fortificants to cereals have been shown to enter a 'common non-haem-Fe pool' and are absorbed to the same extent as the intrinsic food $\mathrm{Fe}$ (Layrisse \& Martinez-Torres, 1971; Cook et al. 1972; Björn-Rasmussen \& Hallberg, 1972). Although $\mathrm{Fe}$ (III)EDTA appears to form a common pool with food $\mathrm{Fe}$ in some situations it is preferentially absorbed in others. Thus when Fe(III)EDTA was cooked with either maize porridge or a pea-based dhal, absorption of extrinsic Fe(III)EDTA:absorption of intrinsic food Fe was close to unity. However, absorption of Fe from Fe(III)EDTA added to pre-cooked maize porridge was 3-fold higher than that of the intrinsic maize $\mathrm{Fe}$, which was presumably due to incomplete mixing. It should be noted that even when the relative absorption value was close to unity the absorption of the radio-Fe added as Fe(III)EDTA was always marginally greater. A similar deduction can be made from results obtained by Layrisse and co-workers (Layrisse \& Martinez-Torres, 1977; Martinez-Torres et al. 1979). Statistical analysis of their values using Student's $t$ test for paired values indicates the absorption from $\mathrm{Fe}(\mathrm{III}) \mathrm{EDTA}$ ( $5 \mathrm{mg}$ and $50 \mathrm{mg} \mathrm{Fe}$ ) given in a maize-soyabean meal was significantly greater than from the intrinsic $\mathrm{Fe}(t 3.54, P<0.005 ; t 5.04, P<0.005$ respectively). This may indicate that the $\mathrm{Fe}$ in the Fe(III)EDTA complex may frequently not exchange completely with the intrinsic Fe or indeed with added Fe salts. Evidence that there is indeed an exchange between the Fe in the EDTA complex and other Fe salts was provided by the demonstration of both ${ }^{55} \mathrm{Fe}$ and ${ }^{58} \mathrm{Fe}$ in the urine of subjects given porridge fortified with ${ }^{55} \mathrm{Fe}(\mathrm{III}) \mathrm{EDTA}$ and ${ }^{59} \mathrm{FeSO}_{4} \cdot{ }_{7} \mathrm{H}_{2} \mathrm{O}$. Since none of the $\mathrm{Fe}$ absorbed from ${ }^{59} \mathrm{FeSO}_{4} \cdot 7 \mathrm{H}_{2} \mathrm{O}$ is excreted in the urine, the appearance of almost equal quantities of the two isotopes in the urine implies that almost complete exchange must have occurred in the lumen of the gut. This exchange process was confirmed in vitro by the enhanced solubilization of ${ }^{59} \mathrm{Fe}$ from ${ }^{58} \mathrm{FeSO}_{4} .7 \mathrm{H}_{2} \mathrm{O}$-fortified maize porridge by the addition of unlabelled $\mathrm{Fe}$ (III)EDTA. The relatively good absorptions seen when Fe(III)EDTA was used to fortify cereal-based meals can probably be ascribed to the fact that $\mathrm{Fe}$ in the form of the $\mathrm{Fe}(\mathrm{III})$ EDTA complex remains in solution and relatively unaffected by inhibitory ligands in food even at $\mathrm{pH} 5$. Thus in the region of the duodenum and jejunum, where most $\mathrm{Fe}$ absorption takes place, the $\mathrm{Fe}$ is in a highly-soluble form and formation of insoluble, poorly-absorbed $\mathrm{Fe}$ complexes is prevented. There is one final point concerning the exchange of $\mathrm{Fe}$ between $\mathrm{Fe}$ (III)EDTA and intrinsic food $\mathrm{Fe}$ which merits comment. In one experiment $\mathrm{FeSO}_{4}$ was given with porridge on one morning and $\mathrm{Fe}$ (III)EDTA was fed on the other. Since both $\mathrm{Fe}$ compounds form a common pool with food $\mathrm{Fe}$ it would have been expected that $\mathrm{Fe}$ absorption on the 2 days would have been the same. It was, however, twice as great when the fortificant was Fe(III)EDTA. This suggests that the mechanism whereby $\mathrm{Fe}(\mathrm{III})$ EDTA forms a common pool with intrinsic Fe differs from simple Fe salts. The apparent enhancement of intrinsic food $\mathrm{Fe}$ absorption by $\mathrm{Fe}$ (III)EDTA, which was also previously noted by Layrisse \& Martinez-Torres (1977), could be due to an exchange of 
isotope between intrinsic ${ }^{55} \mathrm{Fe}$ and ${ }^{59} \mathrm{Fe}$ in the EDTA chelate. The intrinsic ${ }^{55} \mathrm{Fe}$ which complexes with EDTA remains in solution and is well absorbed. On the other hand, in the instance of simple Fe salts no 'solubilizing' chelate is present and the $\mathrm{Fe}$ is bound to inhibitory ligands in the food and is as poorly absorbed as the intrinsic Fe.

The fact that small amounts of radio-Fe appeared in the urine after ingestion of labelled Fe(III)EDTA indicates that some of the Fe was probably absorbed intact in the form of the Fe(III)EDTA complex, since Fe and other EDTA chelates have been shown to be rapidly excreted by the kidney (Will \& Vilter, 1954). In the present study all radio-Fe was excreted in 18-24 $\mathrm{h}$ and in no subject did the amount exceed $1 \%$ of the administered dose. An inverse relationship was noted between the Fe absorbed and the Fe appearing in the urine (Fig. 1) which suggests that less Fe was absorbed as the chelate when the mucosa was avid for Fe. At the same time, it was noteworthy that most of the Fe was probably absorbed in a non-chelated form, even by individuals who were not Fe-deficient. Whether the Fe dissociates from the complex before entering the mucosa or within the mucosa is not clear.

The results of the present study confirm the potential usefulness of Fe(III)EDTA as an Fe fortificant (Layrisse \& Martinez-Torres, 1977; Martinez-Torres et al. 1979). It can be added to food with little or no colour change and is well absorbed even in the presence of known inhibitors. If it can be shown that the long-term administration of Fe(III)EDTA does not adversely affect trace mineral metabolism, then it may well fulfil an important role in Fe-fortification programmes.

This work was supported by grants from the South African Atomic Energy Board and the South African Sugar Association. The authors are indebted to Mrs Uta Schmidt, Mrs Devi Moodly, Miss Fawzia Khan and Mrs Jane Lamprey for their invaluable assistance.

\section{REFERENCES}

Bezwoda, W., Charlton, R., Bothwell, T., Torrance, J. \& Mayet, F. (1978). J. Lab. clin. Med. $92,108$.

Björn-Rasmussen, E. \& Hallberg, L. (1972). Am. J. clin. Nutr. 25, 317.

Björn-Rasmussen, E. \& Hallberg, L. (1974). Nutr. Metab. 16, 94.

Bothwell, T. H., Charlton, R. W., Cook, J. D. \& Finch, C. A. (1979). In Iron Metabolism in Man, p. 443. Oxford: Blackwell.

Cook, J. D., Layrisse, M., Martinez-Torres, C., Walker, R. B., Monsen, E. \& Finch. C. A. (1972). J. clin. Invest. 51, 805.

Deppe, W. M., Joubert, S. M. \& Naidoo, P. (1978). J. clin. Path. 31, 145.

Derman, D., Sayers, M., Lynch, S. R., Charlton, R. W. \& Bothwell, T. H. (1977). Br. J. Nutr. 38, 261.

Disler, P. B., Lynch, S. R., Charlton, R. W., Bothwell, T. H., Walker, R. B. \& Mayet, F. (1975). Br. J. Nutr. 34, 141.

Disler, P. B., Lynch, S. R., Charlton, R. W., Torrance, J. D., Bothwell, T. H., Walker, R. B. \& Mayet, F. (1975). Gut 16, 193.

Hallberg, L., Björn-Rasmussen, E., Garby, L., Pleehachinda, R. \& Suwanik, R. (1978). Am. J. clin. Nutr. 31, 1403.

Herbert, V., Gottlieb, C. W. \& Lau, K. S. (1967). J. nucl. Med. 8, 529.

Hussain, R., Walker, R. B., Layrisse, M., Clark, P. \& Finch, C. A. (1965). Am. J. clin. Nutr. $16,464$.

International Commission for Radiation Protection (1960). Report of Committee 1l on Permissible Dose of Internal Radiation 1959. ICRP Publication no. 2 Oxford: Pergamon Press.

International Committee for Standardisation in Haematology (1978), Br. J. Haemat. 38, 291.

International Nutritional Anemia Consultative Group (1977). Guidelines for the Eradication of Iron Deficiency Anaemia, p. 16. New York: Nutrition Foundation.

Jacobs, A., Miller, F., Worwood, M., Beamish, M. R. \& Wardrop, C. A. (1972). Br. med. J. iv, 206.

Katz, J. H., Zoukis, M., Hart, W. L. \& Dern, R. J. (1964). J. Lab. clin. Med. 63, 885.

Kuhn, I. N., Monsen, E. R., Cook, J. D. \& Finch, C. A. (1968). J. Lab. clin. Med. 71, 715.

Layrisse, M., Cook, J. D., Martinez-Torres, C., Roche, M., Kuhn, I. N., Walker, R. B. \& Finch, C. A. (1969). Blood 33, 430.

Layrisse, M. \& Martinez-Torres, C. (1971). Prog. Haemat. 7, 137.

Layrisse, M. \& Martinez-Torres, C. (1977). Am. J. clin. Nutr. 30, 1166

Layrisse, M., Martinez-Torres, C., Cook, J. D., Walker, R. \& Finch, C. A. (1973). Blood 41, 333.

Lorber, L. (1927). Biochem. Z. 181, 391.

Martinez-Torres, C., Romano, E. L., Renzi, M. \& Layrisse, M. (1979). Am. J. clin. Nutr. 32, 809. 
Mayet, F. G. H., Adams, E. B., Moodley, T., Kleber, E. E. \& Cooper, S. K. (1972). S. Afr. med. J. 46, 1427.

Sawyer, D. T. \& McKinnie, J. M. (1960). J. Am. Chem. Soc. 82, 4191.

Sayers, M. H., Lynch, S. R., Charlton, R. W. \& Bothwell, T. H. (1974), Br. J. Nutr. 31, 367.

Sayers, M. H., Lynch, S. R., Charlton, R. W., Bothwell, T. H., Walker, R. B. \& Mayet, F. (1974). Br. J. Haemat. 28, 483 .

Sayers, M. H., Lynch, S. R., Jacobs, P., Charlton, R. W., Bothwell, T. H., Walker, R. B. \& Mayet, F. (1973). Br. J. Haemat. 24, 209.

Will, J. J. \& Vilter, R. W. (1954). J. Lab. clin. Med. 44, 499. 